\title{
Pseudocyesis and a Maternity Delirium: A Case Report
}

\author{
Maryam Abrache $^{1^{*}}$, Sara Ennazk ${ }^{1}$, Imane Adali ${ }^{1}$, Fatiha Manoudi ${ }^{1}$
}

\author{
${ }^{1}$ Mental Health Research Team, Ibn Nafis Psychiatric Hospital, Mohamed VI University Hospital, Marrakesh, Morocco \\ DOI: $10.36347 /$ simcr.2021.v09i03.010 \\ | Received: 26.02.2021 | Accepted: 09.03.2021 | Published: 10.03.2021 \\ *Corresponding author: Maryam Abrache

\section{Abstract} \\ The definition of pseudocyesis consists of the delusional conviction of being pregnant accompanied by objective signs \\ and symptoms of pregnancy despite a negative paraclinical assessment mainly comprising the BHCG assay. We report \\ here the case of a patient who presented a maternity delirium following pseudocyesis, discussing this case in the light \\ of the literature. \\ Keywords: Pseudocyesis, maternity delirium, Case Report. \\ Copyright () 2021 The Author(s): This is an open-access article distributed under the terms of the Creative Commons Attribution 4.0 International \\ License (CC BY-NC 4.0) which permits unrestricted use, distribution, and reproduction in any medium for non-commercial use provided the original \\ author and source are credited.
}

\section{INTRODUCTION}

Pseudocyesis is when a person has an unreal belief of being pregnant associated with the objective symptoms of pregnancy, it is one of the most interesting issues for women at reproductive age or even close to menopause.

This syndrome described since antiquity remains little known because it is rare and insufficiently addressed in the literature. Even more exceptional is the occurrence of maternity delirium in the patient in question. The processes behind these troubles are not yet clear. We wish to present the original case of a patient who presents with pseudocyesis followed by a delirium of maternity. To our knowledge, only 2 cases of pseudocyesis followed by a delirium of maternity have been reported in the literature $[1,2]$.

\section{Patient and Observation}

Miss B.S 36 years old, was married for 10 years, second in a family of 4 kids, housewife, primary school level, with no particular pathological history. The patient has never become pregnant since her marriage apart from a miscarriage 5 years ago.

The patient was presented to the psychiatric emergency room following a feeling of dread and psychomotor agitation. The interview found a restless patient with strange contact, inconsistent speech, poorly systematized delirium centered around the themes of persecution and bewitching towards some members of her family, auditory and visual hallucinations, the patient had abdominal enlargement and has reported that she is pregnant and it's her 8th month of amenorrhea and told us that she feels fetal movement in her lower abdomen. A standard biological assessment was requested, returned normal apart BHCG negative and an abdominal pelvic echography was done and found an empty uterus with no abdominal or pelvic mass. A brain CT scan was done, revealing no abnormalities. At the end of clinical investigations, we have concluded that it was an acute psychotic episode with pseudocyesis. The patient and her family refused hospitalization, we put the patient on olanzapine 10 $\mathrm{mg}$ /day combined with lorazepam $7.5 \mathrm{mg} /$ day and we gave her an appointment in a week, but the patient was not seen again until two months later with a delirium of maternity, confirmed by the testimony of her family. Neuroleptic treatment was continued, with psychotherapy planned, but the patient was lost to follow-up for a year. When the patient was seen again, it was found in the psychiatric interview that the patient no longer presented with pseudocyesis or maternity delirium, but that she still had the delirium of persecution and bewitching. The patient has improved considerably after a few months of treatment and so far, does not present any delirium.

\section{DISCUSSION}

The Diagnostic and Statistical Manual of Mental Disorders-5 (DSM-5), released pseudocyesis as a person's false belief to be pregnant, accompanied by objective symptoms and signs of pregnancy with symptoms similar to uterine contraction at the expected date of delivery, even though the person concerned is not pregnant; it can also be associated with abdominal 
enlargement, amenorrhea or oligomenorrhea, breast engorgement, nausea, secretions and a subjective sensation of fetal movement [3]; researchers from Monash University have published a new study on the sensations of "phantom" fetal kicks and they reported that $12.8 \%$ of women say they feel happy and comforted by the experience [4]. Affected women may have an increased appetite and as a result a gain of weight, they may also have the lordotic posture of a pregnant woman $[5,6]$. Symptoms of pseudocyesis are usually last for nine months but may persist longer, they mostly affect young women, with an average age of 33, mostly married and childless [7], these factors are almost all present in the story of our patient. The recurrence of pseudocyesis is seen mainly in psychotic patients [8]; a single case of pseudocyesis with bipolar disorder was published in the literature [9]. Pseudocyesis can be related to an intense desire to get pregnant, or an intense fear of getting pregnant, which can create changes in the endocrine system [10]; such as growth hormone, prolactin, ACTH, cortisol and FSH / LH [8]. There is no consensus on management yet, but the use of supportive psychotherapy seems the most appropriate [11].

\section{Conclusion}

Pseudocyesis is a rare disorder often associated with other psychiatric comorbidity. However, it remains relatively more common where fertility is highly valued in society, especially in women.

\section{REFERENCES}

1. Pirtovsek Savs A, Derganc M, Licina $M$. Pseudocyesis followed by delusions of maternity. European psychiatry, 2012;27(supplement 1).
2. Kettani N, Rharrabti S, Hlal H, Aalouane R, Rammouz I. Délire de maternité dans les suites d'un pseudocyesis. 2013.

3. Arlington V. Diagnostic and Statistical Manual of Mental Disorders (5th Ed). American Psychiatric Publishing, Virginia; 2013. 10.1176/appi.books.9780890420249.dsm-iv-tr

4. Sasan D, Ward PG, Nash M, Orchard ER, Farrell MJ, Hohwy J, Jamadar SD. Phantom Kicks: Women's Subjective Experience of Fetal Kicks After the Postpartum Period. Journal of Women's Health, 2021;30(1):36-44.

5. Yanti L. O lord... where is my fetus?: a case report of pseudocyesis. Medisains. 2019;17(2):47.

6. Thippaiah Hippai S, George V, Birur B, Pandurangi A. A Case of Concomitant Pseudocyesis and Couvade Syndrome Variant. Psychopharmacol Bull. 2018; 48(3): 29-32.

7. Paulman PM, Sadat A. Pseudocyesis. J Fam Pract. 1990;30(5):575-6.

8. Shiwach RS, Dudley AF. Delusional pregnancy with polydipsia: a case report. J Psychosom Res. 1997;42(5):477-80.

9. Espiridion ED, Fleckenstein C, Boyle P, Oladunjoye AO. A Rare Case of Pseudocyesis in a Patient With Bipolar Disorder. Cureus. 2020 Sep;12(9):e10352.

10. Anoosheh M, Hamednia S. A Case Report of Delusional Pregnancy/Pseudocyesis in A 66 Years Old Woman With A Bipolar Mood Disorder In Urmia. Urmia Medical Journal, 2020;30(10):831835.

11. Kaplan HI, Saddock BJ. Synopsis of Psychiatry. Baltimore: Williams \& Wilkins; 1997. 